\title{
Expanding applications of virtual reality in construction industry: A multiple case study approach
}

\author{
G. Ozcan-Deniz ${ }^{*}$ \\ Thomas Jefferson University, College of Architecture and the Built Environment, Philadelphia, PA, USA
}

\begin{abstract}
Recent developments in the Virtual Reality (VR) have positively affected the way design and construction parties understand, revise, and complete building projects. VR offers unique capabilities such as stepping into a 3D model of the building during early design stages and maneuvering with interactive features in the virtual environment. With these opportunities, designers, contractors, and owners can now share data and make crucial decisions even before the model is implemented at the construction site. A variety of applications and uses of VR are possible for contractors, yet the detailed analysis of key enablers and challengers from general contractors' (GC) perspective is missing. This study aims to perform a detailed review of VR applications in the construction industry by conducting a multiple case study approach. Data collection was performed on twenty-seven (27) case studies from eighteen (18) construction companies in the U.S. to report the uses and benefits of VR in the construction industry from GCs' perspective. Findings revealed the main uses of VR as design reviews for clients and occupants, project coordination, monitoring the construction process, and training. The greatest value of the VR technology was reported as decreasing cost, optimizing schedules, streamlining the occupant-related decision process, and enhancing collaboration. All companies have been using immersive VR technology, which showed their investment and commitment to this emerging technology and its benefits in the construction industry. Future studies are planned to compare applications of VR in academia vs. in construction industry to close the gap of knowledge between educators and practitioners.
\end{abstract}

\section{Keywords}

Virtual reality; Construction industry; Industry applications of virtual reality; Immersive virtual reality

Received: 24 April 2019; Accepted: 11 June 2019

ISSN: 2630-5771 (online) @ 2019 Golden Light Publishing All rights reserved.

\section{Introduction}

Virtual Reality (VR) has been an emerging technology that is popular due to its capabilities such as simulating complex systems and offering improved visualization and high levels of interactivity [1]. VR has been changing construction industry by shifting the way construction is performed using 3D modeling. Although 2D and 3D models have been widely used in the industry before, placing user directly in the model has presented the opportunity to acquire information from experiences created in a sensory system. Computer generated model (a.k.a. 3D model) is used as a virtual environment, where users interact with the building and collect sensory input. Users feel to be actually and actively present in the virtual environment at different stages of construction instead of trying to imagine changes in time phases [2]. With its future prediction

* Corresponding author

Email: gulbin.deniz@jefferson.edu 
capabilities and reflecting design alternatives in the 3D building model, owners and future occupants can visualize the final stages of the building well before construction is finished [3].

The uses of VR in architecture and construction have widespread in different concentration areas. The benefits of VR for designers and the implications of designs on safety were found apparent in a recent study [4]. The study brought design professionals to a virtual construction site to perform safety reviews. Results showed the importance of consultation and dialogue with an experienced construction professional through virtual reality. Another study expanded the improved visualization capabilities of VR by linking the technology to field construction planning [5]. The benefits of VR in different construction phases such as design, construction, and operation were highlighted in various studies in relation to compatibility with other systems [6] and collaboration [7]. With the abundance of studies concentrating on the benefits of VR in design and construction, one will need to look deeper to reveal the enablers and challengers associated with VR for contractors. This study aims to fulfill the gap of VR analysis from a contractors' perspective by conducting a detailed review of VR applications in the construction industry. Around this major goal, the objectives of this study can be summarized to:

- Evaluate key enablers and challengers from contractors' perspective

- Identify the main uses of VR by contractors

- Highlight the most widely used VR technology from contractors

- Analyze main project benefits in relation to the use of VR

Following sections include background information of VR history and uses, identification of VR enablers and challengers for contractors, and details of case studies such as type of VR technology used in each case, how VR was used, and how the technology benefited the company and the project. Findings and Discussions section will include discussions related to the top main uses of VR by contractors.

\section{Background}

Immersive VR is defined as a computer-generated system of 3D images or environment that allows a certain level of interaction in a physical manner with the help of a Head Mounted Device (HMD), controllers/gloves with sensors, and a display screen [8]. VR use has first started with HMD devices to train fighter pilots [9]. The technology was found effective for simulation of complex systems, visualization, fast and slow time simulation, high levels of interactivity, and inherent flexibility/adaptability [1]. VR has been implemented in different platforms ever since. It has been widely used for training purposes, such as to enhance worker ability for a particular construction work [10] and to train crane and excavator operators with a Building Information Modeling (BIM) and real-time location tracking technology in VR [11].

The main reason why training was very popular in VR applications has been due to the safety concerns in an actual construction site. Therefore, many of the related studies have focused on designing a VR-based system to improve safety and health in construction projects. As an example, a social VR system framework was proposed to perform role-playing, dialogic learning, and social interaction for construction safety and health education [12]. Another example was on a VRbased safety training program for design and installation of electrical systems [13]. The proposed platform allowed workers to effectively rehearse tasks with electrical hazards and ultimately promote their abilities for electrical hazard cognition and intervention. Other areas of VR use involved visualization of construction plans and schedules [14], communicating and training the project team [14], as well as construction scheduling and interactive site experiences [15].

In the overall, VR presents a great potential in construction industry with its various uses and due to its capability of providing a realistic and safe experience in a first-person setting [16]. In order to fully benefit from its capabilities for contractors, a detailed analysis of VR key enablers and challengers in construction is needed. First step in 
this study will be to identify enablers and challengers from literature.

\subsection{Defining enablers and challengers}

Enablers of VR implementation in this study can be defined as benefits and significant project outcomes of using VR from contractors' perspective. A list of enablers is presented below:

1. Improving Communication / Collaboration / Coordination:

Collaboration in VR was defined as the communication and coordination between various stakeholders of the construction project, which includes designer, contractor, client, and occupants. Many of the previous studies mentioned how VR improved collaboration and communication within and outside the contractor's team, while enabling coordination in-between various disciplines to sustain clash detection (e.g. [17], [18], [19], [20], [21], [22], [8]).

\section{Cost/Time Savings:}

The major benefit of any emerging technology for construction is evaluated based on two main parameters: cost and time for contractors, as they need to finish all projects in budget and on time. Although cost and time savings are also outputs of other enablers mentioned in this paper, benefits in terms of project budget and duration were highlighted in several studies (e.g. [18], [23], [8]).

\section{Improving Design Review:}

VR has been widely used to show the intended product to clients and occupants, especially in hospital and other medical building projects [24]. Previous studies noted how clients change their preferences in design when they can see the impact of their decisions in VR [8]. Additionally, design reviews offer value engineering opportunities to improve cost savings, while maintaining client satisfaction for future projects. VR has been proposed to be an effective tool for design review and assessment by many other studies in literature (e.g. [25], [18], [26]).

As a secondary benefit VR offers improved visualization. Though visualization has been main concern of Architects and other design parties, contractors have benefited from improved graphics to show the construction project to clients and occupants. With immersive VR and high-end visualization, clients and occupants are engaged in the project, which enables the collection of proper and timely feedback during design reviews.

\section{Improving Safety/Training:}

Construction projects have benefited from VR for worker training and safety management, which were linked to one another in many cases. Effective training of workers in dangerous conditions such as operating heavy and medium construction equipment was practiced many times with the VR technology due to providing a safe way to educate project personnel. As an example, an interactive virtual training model called Safety in construction using Virtual Reality (SAVR) was developed to train workers against falls [27]. Another study focused on tower crane dismantlement and proposed a multiuser virtual safety training system (MVSTS) aimed at teaching the correct dismantling procedure and working location for the process [28]. Many other studies highlighted the impact of VR to improve safety at the site (e.g. [29], [23], [30]).

\section{Improving Construction Site Process:}

Visual site planning and monitoring has been a topic of interest for the recent years. A previous study proposed the use of a computer-based system for visual planning and created virtual construction project [31]. Another study aimed to sustain a safe and efficient site by simulating the layout of construction site facilities [32]. Simulation of the construction process to immerse users in a proposed site plan and alter construction site studies were recently studied for a studio project [33], which links the success of immersive VR site planning to long-term scheduling benefits.

Challengers of VR implementation in this study can be defined as limitations of the VR tools, as well as requirements of VR that may prevent contractors to adopt and implement this emerging technology. A list of challengers is presented below: 
1. Preparation of the 3D Model:

VR requires a completed 3D model of the building for a proper visual immersive experience. Some of the previous studies used computer-aided design (CAD) to create 3D models and mentioned the lack of overlap between CAD and VR skills as a major challenger to implement VR in the construction industry [34]. Some others used 4D CAD modeling (3D model plus time) to be used with advanced visualization tools for developing and communicating construction plans [15]. Many of the other studies have used 3D models created by BIM software to achieve a virtual environment. For example, BIM was integrated with 2D images on job site to understand the most efficient training styles for safety with the help of hazard training modules [35]. Another study used a virtual BIM environment for collaboration for virtual on-site visits to discuss Heating, Ventilation and Air Conditioning (HVAC) systems [36]. By storing different disciplines' plans and information, BIM allows many applications along the design and construction process, including cost-estimation, energy analysis and production planning [37]. However, with the variety of requirements and details in creating 3D models, the preparation of the model itself presents a challenge to perform virtual walk-throughs in buildings.

\section{Lack of Streamlined Software:}

Previous studies experimented virtual environment with various software applications and found interoperability issues [36]. BIM-related visualization was practiced from many ends, such as improving quality, construction scheduling and interactive site experiences [15], cost-estimation, energy analysis and production planning [37]. Multiple approaches require multiple software applications, which makes it very challenging to create streamlined software applications that can be used by designers, contractors, and other project parties. Previously, a typical BIM to VR software workflow was proposed to: (1) To create a 3D model by using Autodesk Revit, (2) To involve Autodesk 3DS Max for model optimization and bake lighting, and (3) To include Unity and
WorldViz for stereoscopic immersive VR experience [38]. In this example, several steps of optimization and increased visualization were performed to make sure complex models were ready for the virtual world. The length and complexity of this process is a main challenge for VR implementation due to requiring multiple software applications to be used to create a virtual environment and perform a virtual walk-through.

3. Virtual Model Rendering Issues:

In order to create a virtual equivalent of a real building project, virtual image qualities should be sustained with a high quality of graphics and rendering. Some studies already mentioned that VR lacked a high degree of realism due to the virtual model being created with arbitrary geometric and orientation values [39]. Poorly rendered models were claimed to prevent VR user's understanding of the actual design. Examples have been persistent especially with cases where CAD is used to created $3 \mathrm{D}$ models due to its focus on geometric modeling rather than presentation of construction elements [40].

\subsection{Types of VR technology}

VR technologies can be mainly categorized into two as: (1) non-immersive (a.k.a. desktop-based VR and (2) immersive VR. Desktop-based VR is the easiest technology to adopt due to the low-cost and training associated with the technology. It only requires a gaming laptop/PC and is operated on a desktop screen through the use of a mouse and a keyboard. There are no tracking devices, sensors, or goggle associated with this technology [41].

An immersive VR system includes the use of an HMD or goggles with handheld devices such as controllers of sensory gloves. User only sees images in the virtual environment to sustain full immersion. With the help of a gaming laptop/PC and projector, user's view is projected to a TV or monitor for the whole construction team to be involved in the virtual walk-through process [42]. As a secondary type of immersive VR, user stands inside a spatially immersive display (SID). Although there are various levels of immersion, the 
idea is to create a spatial immersion with graphics so that the user observes the virtual world as real [26]. CAVE Automatic Virtual Environment (CAVE) is a typical example of a SID, where an immersive virtual environment is created around the user to embed real-time capabilities [43]. CAVE uses 4-6 large projection screens in the shape of a cube, where the user walks into. With the use of a projector, stereo graphics are projected among the walls of the cube, so that user only sees these images and himself/herself to be fully immersed in the virtual environment [44].

\section{Methodology}

The methodology starts with identifying construction companies that use VR effectively (Fig. 1). Companies were identified through reliable General Contractor (GC) database such as Engineering News Record (ENR) and through previous experience and communications with construction companies in the area. Companies were then filtered to include only the ones using any type of immersive VR technology by briefly interviewing company professionals and retrieving information on recent case studies on web sources.
Additionally, companies needed to be filtered once more depending on the accessibility and availability of interviewees. The type of VR technology and equipment used as well as the main VR uses and benefits for the company/project were identified through performing a multiple case study approach. A total of twenty-seven (27) case studies were evaluated through interviews with eighteen (18) companies. The VR data was collected and evaluated over three (3) years of a time-period for this study.

As it can be observed from Table 1, most of the case studies were medical buildings such as multiservice ambulatory care center, university health center, or hospitals. Remaining cases included public schools, campus buildings, high-rise apartments, multi-use buildings, one indoor trampoline center, one river walkway, and one land port of entry. The sizes of medical building projects varied between $100,000 \mathrm{SF}$ to $500,000 \mathrm{SF}$, while other projects varied from $30,000 \mathrm{SF}$ to $250,000 \mathrm{SF}$. In terms of the company properties, among eighteen (18) companies, eight (8) of them made it to the first twenty (20) of the ENR's 2018 Top 400 Contractors list [45].

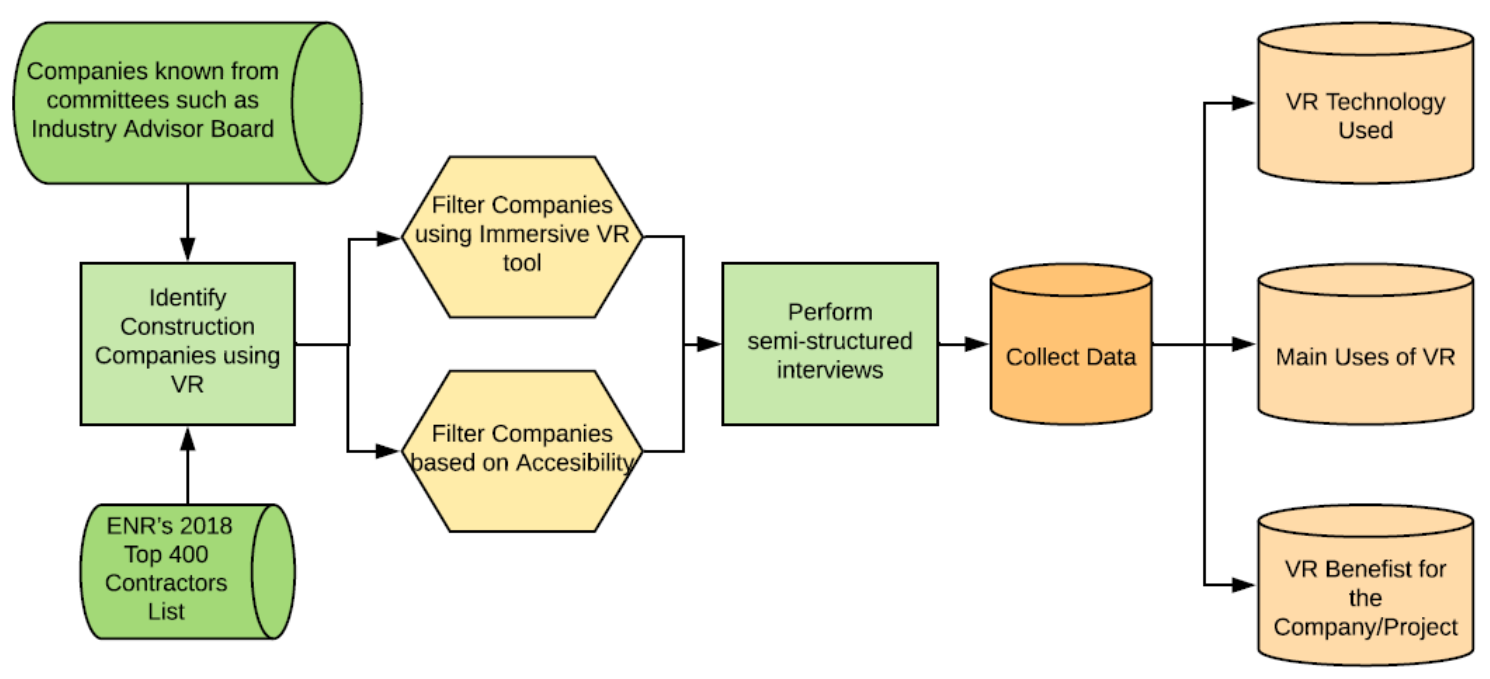

Fig. 1. VR industry applications methodology 
Table 1. General information about case studies

\begin{tabular}{|c|c|c|c|}
\hline Case No & Company & Case Study Type & VR Technology Type \\
\hline 1 & A & Medical Building & $\begin{array}{l}\text { Oculus Rift VR Headset mixed with CAVE and } \\
\text { Xbox remote control }\end{array}$ \\
\hline 2 & A & Medical Building & Oculus Rift VR Headset \\
\hline 3 & A & School Building & HTC Vive VR Headset \\
\hline 4 & A & Medical Building & $\begin{array}{l}\text { Oculus Rift VR Headset and an Xbox remote } \\
\text { control }\end{array}$ \\
\hline 5 & $\mathrm{~B}$ & Medical Building & Oculus Rift VR Headset \\
\hline 6 & B & Headquarter & $\begin{array}{l}\text { WorldViz Architecture Interactive showroom, } \\
\text { HMDs and motion tracking systems }\end{array}$ \\
\hline 7 & B & Medical Building & Oculus Rift VR Headset \\
\hline 8 & $\mathrm{C}$ & $\begin{array}{l}\text { High Rise Apartment } \\
\text { Building }\end{array}$ & $\begin{array}{l}\text { VR headset combined with an app made by } \\
\text { Context VR, which takes 360-degree photos of } \\
\text { construction site }\end{array}$ \\
\hline 9 & $\mathrm{D}$ & Campus Building & Google Cardboard \\
\hline 10 & $\mathrm{E}$ & Indoor Trampoline Center & Render 3D with HMDs \\
\hline 11 & $\mathrm{E}$ & Multi-use Building & Render 3D with HMDs \\
\hline 12 & $\mathrm{~F}$ & Land Port of Entry & Roundme VR with 360-degree photos \\
\hline 13 & G & Multiple Projects & $\begin{array}{l}\text { VRTEX 360, a VR product to simulate welding } \\
\text { process }\end{array}$ \\
\hline 14 & $\mathrm{H}$ & Medical Building & Epic Games (Unreal Engine) with VR headset \\
\hline 15 & I & Medical Building & HMDs with Worldviz \\
\hline 16 & $\mathrm{~J}$ & Medical Building & VR headset combined with an app \\
\hline 17 & $\mathrm{~J}$ & Campus Building & HoloLens \\
\hline 18 & $\mathrm{~J}$ & Campus Building & Oculus Rift VR Headset \\
\hline 19 & $\mathrm{~K}$ & Medical Building & HTC Vive VR Headset \\
\hline 20 & $\mathrm{~K}$ & Medical Building & HTC Vive VR Headset \\
\hline 21 & $\mathrm{~L}$ & Multiple Projects & HoloBuilder/Google Cardboard \\
\hline 22 & M & Medical Building & Virtual Reality Imaging with 360-degree photos \\
\hline 23 & $\mathrm{~N}$ & River Walkway & Oculus Rift VR Headset \\
\hline 24 & $\mathrm{O}$ & Office building & CAVE \\
\hline 25 & $\mathrm{P}$ & Headquarter & HTC Vive VR Headset \\
\hline 26 & Q & Multiple Projects & HTC Vive VR Headset \\
\hline 27 & $\mathrm{R}$ & Medical Building & $\begin{array}{l}\text { HTC Vive Headset, Oculus Rift Headset, } \\
\text { PlayStation VR and OSVR }\end{array}$ \\
\hline
\end{tabular}

This list is created based on construction contracting-specific revenue of companies in the prior year. Additionally, six (6) of the companies were recognized in the top ranking of the nation's largest healthcare sector contractor and construction management firms, as reported in the 2017 Giants 300 Report [46], which proves the considerably large share of these companies in the overall U.S. construction industry, as well as in the healthcare construction. 
The interview process included introduction of the purpose of the study, asking questions about the specific technology used, main uses of technology in the project(s), and main benefits of VR to the company/projects. Interviews were held in a semistructured way to allow interviewees to add to enablers and challengers as they found appropriate to their company. Following sections will include interviewees' responses and basic evaluation of the collected data.

\subsection{Type of VR technology used}

The interviewees were asked to evaluate the effectiveness of the VR technology of their choice in the company. Some companies practiced multiple VR technologies depending on the project type, while others stick to one certain type of VR tool. The majority of the VR technologies reported were immersive with two well-known HMDs that has been used in construction projects for virtual mock ups and design reviews for the past years. First one, Oculus Rift VR Headset is one of the most common VR set, which comes with a headset, touch controllers, and two sensors to translate the movement of the headset and controllers to the virtual environment [47]. Case studies mainly used Oculus Rift in medical building projects to perform design reviews and collect feedback from clients and occupants. A recent study with medical users stated Oculus Rift to be easy to navigate and perform consultations in a secure environment with high image quality [48]. Second mostly stated HMD technology was HTC Vive VR System, which was used with a compatible laptop and a TV as a stereo projector on a screen. HTC Vive brings in fully immersive first-person experience and comes with a headset, two-360-degree controllers, and two base stations to cover user's movements to the millimeter, floor-to-ceiling [49]. Hardware is powered by Steam VR [50] that allows for a roomscale or standstill virtual exploration. When a 3D model is created with Autodesk Revit or any other suitable 3D modeling software, there is an additional software requirement for 3D models to be transferred to the VR software [51]. Medical building projects as well as multi-use projects were reported to use HTC Vive to present the finished 3D model and help occupants understand the changes to the building.

Some companies utilized WorldViz [52], which offers customized VR experiences by using HMD devices in a pre-set virtual environment. ContextVR [53] was another VR technology mentioned during the interviews, which allows taking 360-degree photos of construction sites and storing them in a cloud-based system. Photos are used to create a virtual environment for design reviews, as-built documentation, client updates, and dispute resolution. Some other technologies also included using 3D virtual imaging to create the model and an HMD to perform virtual walkthroughs. HoloBuilder [54] was used to map out the construction site and understand specific site uses. CAVE was also used to immerse users in the planned building model to perform a collaborative evaluation by several parties simultaneously. The detailed uses of these VR technologies will be discussed in the next section.

\subsection{Main uses of VR in construction}

Interviewees were asked to detail their main uses of VR technology in the associated company. The broad list of cases and the uses of VR for each case are presented in Table 2.

As it can be observed from the data presented, the results pointed to some common uses, which can be grouped in four (4) main categories:

\section{(1) Performing design reviews}

The majority of the companies performed design reviews and $3 \mathrm{D}$ virtual mockups to enable designer and non-designer parties to contribute to design development, so that design could be corrected well before the construction had started. VR technology helped occupants to understand the overall design and planned design changes to the building. Designer and contractor parties collected feedback from occupants, which streamlined the occupantrelated decision process. Presenting the finished 3D model to clients allowed early engagement of project parties and helped to identify client needs before any fixed decisions were made. VR aided 
Table 2. Uses of VR in each case study

\begin{tabular}{|c|c|c|}
\hline Case No & Case Study Type & Main Use of VR \\
\hline 1 & Medical Building & $\begin{array}{l}\text { Perform design reviews } \\
\text { Perform virtual mockups in 3D } \\
\text { Help occupants understand the changes to the building } \\
\text { Collect feedback from occupants }\end{array}$ \\
\hline 2 & Medical Building & $\begin{array}{l}\text { Monitor construction process } \\
\text { Identify client needs }\end{array}$ \\
\hline 3 & School Building & $\begin{array}{l}\text { Present the finished 3D model } \\
\text { Help occupants understand the changes to the building } \\
\text { Collect feedback from occupants }\end{array}$ \\
\hline 4 & Medical Building & Perform project coordination \\
\hline 5 & Medical Building & $\begin{array}{l}\text { Perform design reviews } \\
\text { Perform virtual mockups in 3D } \\
\text { Help occupants understand the changes to the building } \\
\text { Collect feedback from occupants }\end{array}$ \\
\hline 6 & Headquarter & $\begin{array}{l}\text { Perform design reviews } \\
\text { Use rapid prototyping to streamline design changes }\end{array}$ \\
\hline 7 & Medical Building & $\begin{array}{l}\text { Present the finished 3D model of the project } \\
\text { Help occupants understand the changes to the building } \\
\text { Collect feedback from occupants }\end{array}$ \\
\hline 8 & $\begin{array}{l}\text { High Rise Apartment } \\
\text { Building }\end{array}$ & $\begin{array}{l}\text { Keep records of the project on mobile devices } \\
\text { Monitor management and safety on the site } \\
\text { Photograph and see different parts of the project } \\
\text { Share virtual information with stakeholders }\end{array}$ \\
\hline 9 & Campus Building & $\begin{array}{l}\text { Perform occupant reviews } \\
\text { Collect feedback from occupants }\end{array}$ \\
\hline 10 & $\begin{array}{l}\text { Indoor Trampoline } \\
\text { Center }\end{array}$ & $\begin{array}{l}\text { Perform virtual mockups in 3D } \\
\text { Have real time visualization of the projects }\end{array}$ \\
\hline 11 & Multi-use Building & $\begin{array}{l}\text { Perform virtual mockups in 3D } \\
\text { Have real time visualization of the projects }\end{array}$ \\
\hline 12 & Land Port of Entry & $\begin{array}{l}\text { Perform security analysis } \\
\text { Perform design reviews } \\
\text { Help occupants understand the changes to the building } \\
\text { Collect feedback from occupants }\end{array}$ \\
\hline 13 & Multiple Projects & $\begin{array}{l}\text { Effectively train welders } \\
\text { Monitor inexperienced welders on their skill and performance }\end{array}$ \\
\hline 14 & Medical Building & $\begin{array}{l}\text { Perform occupant reviews } \\
\text { Collect feedback from occupants }\end{array}$ \\
\hline 15 & Medical Building & $\begin{array}{l}\text { Perform virtual mockups in 3D } \\
\text { Perform occupant reviews } \\
\text { Collect feedback from occupants } \\
\text { Improve fit of expensive equipment (such as MRI equipment) }\end{array}$ \\
\hline 16 & Medical Building & $\begin{array}{l}\text { Map out the entire construction process } \\
\text { Perform design reviews } \\
\text { Decrease change orders }\end{array}$ \\
\hline
\end{tabular}


Table 2. Cont'd

Campus Building

Campus Building

Medical Building

Medical Building

Multiple Projects

Medical Building

River Walkway

Office building

Headquarter

Multiple Projects

Medical Building
Perform design reviews

Decrease change orders

Analyze crane placement during steel erection

Perform project coordination

Combine BIM with laser scanning using drones to foresee conflicts
Perform virtual mockups in 3D
Perform occupant reviews
Collect feedback from occupants
Perform virtual mockups in 3D
Perform occupant reviews
Collect feedback from occupants

Map out the site

Integrate safety practices

Manage and train safety procedures before construction

Perform virtual mockups in 3D

Collect feedback from occupants

Perform design review for steel piers

Perform virtual mockups on how to assemble the steel structure

Perform site design reviews

Collect feedback from occupants

Perform design review

Collect feedback from occupants

Simulate every light beam from the sun into the building for every hour of the day for every single day of the year

Perform design review

Perform efficient MEP pipe routing

Perform virtual mockups in 3D

Perform occupant reviews

Collect feedback from occupants designers and contractors with the placement of not only critical but also not critical items from small objects like beds to large equipment like MRI machines. Interviewees stated that the use of VR headsets with the BIM technology allowed doctors and nurses to experience complete immersion and move objects around in the room to the exact location required. Feedback collected from doctors and nurses was also very accurate and helpful leading to easy fixes in VR that can be transferred back to BIM. In several medical buildings, the VR mockup cost was reported to be less than $15 \%$ of the proposed physical mockup. The entire process of conducting early design reviews with VR was mentioned to decrease change orders and save time for all involved parties.

\section{(2) Performing project coordination}

In relation to design reviews, finished 3D models of the building at the design phase were used to sustain communication and collaboration among parties. GC hold the responsibility to make sure designs from architect and structural, mechanical, and electrical engineers should fit and work well in the whole building system. Although clash detection can be performed with some software applications such as Revit and Navisworks, having a virtual walk-through around the building allowed to find the missing clashes and negotiate on how to fix interferences at the spot with various parties. 
Lengthy future paperwork was avoided with the help of BIM-based VR technology.

(3) Monitoring the construction process

A portion of interviewees reported the use of VR to map out the construction site. This process enabled the integration of safety practices and managing safety procedures before the actual construction. When this process was utilized by a cloud-based app, it enabled crowdsourcing site-related essential information to all stakeholders. VR aid in construction site planning not only engaged stakeholders, but also improved safety in the overall construction site due to creating a complete understanding of specific site conditions and dangerous areas beforehand. In a specific case, VR was used to analyze crane placement and avoid conflicts during steel erection. The technology minimized the site logistics risk that was reported due to tower crane risk, as tower crane was to be mantled and operated while keeping student and food services running at a campus project site.

(4) Training

VR technology was effectively used for training in certain case studies. The cases where actually training specific trades at the side was extremely dangerous, VR technology was used to train and monitor inexperienced workers. Welding was one of the popular trades that benefited from the safe VR environment for learning and practice purposes. Welding trade has been necessary for all types of construction projects, yet it was also a skill that has been extremely challenging to teach, due to the danger of the equipment used and the leveling heights associated with different types of projects such as high-rise buildings. The simulator created based on the VR technology allowed workers to get a good idea of pressure, timing, and application of work sets without any risk being involved. The VR training simulator was reported to cut the costs of training new workers dramatically and as being the most realistic VR simulator on the market built for this specific use.

\subsection{VR benefits for the company/project}

VR benefits for twenty-seven (27) case studies and eighteen (18) companies interviewed are presented in Table 3. As it can be observed from the presented data, VR uses by GC companies are in line with the enablers identified in this study. The majority of companies reported direct benefits in 'Lowering Costs and Optimizing Construction Schedules', while others have had indirect benefits on the cost and duration of the project due to improved visualization and enhanced collaboration and communication among project participants throughout the project. More than half of the projects used VR for 'Improving Design Review' and tailored each of its customer's VR experience specific to their needs. VR aid in design reviews was reported to shorten design time and help companies to save money and time throughout the construction project. Additionally, 'Improving Communication/Collaboration/Coordination' has been stated as one of the enablers from literature review and ranked as second as a major VR benefit for GC companies by the interviewees. Improved collaboration was stated due to engaging clients and occupants in early stages of the project, which enables to change or correct design in preconstruction stages of the project. The collaborative VR review process streamlines occupant-related decision process, while improving customer satisfaction. It was interesting to see that several interviewees mentioned one of the benefits of using VR technology was to set the company apart from their competitors. Companies aimed to attract more customers and sustain future relationships with the current customers with the help of using this emerging technology throughout the project design reviews. As VR supplied a protected virtual environment, it gave opportunities to plan and train for specific and traditionally dangerous job tasks at the site. The overall planning of the construction site for critical equipment such as cranes were performed with VR by some companies. These companies emphasized 'Improving Safety / Training' and 'Improving Construction Site Process' as main uses of VR in their areas of operation. A numerical analysis on VR enablers based on interviewees' responses will be presented in the Findings and Discussions section. 
Table 3. Reported VR benefits from case studies

\begin{tabular}{|c|c|c|c|}
\hline Case No & Company & Case Study Type & VR Benefits \\
\hline 1 & A & Medical Building & $\begin{array}{l}\text { Lower costs } \\
\text { Optimize schedules } \\
\text { Engage occupants } \\
\text { Collect proper and timely feedback } \\
\text { Streamline occupant-related decision process } \\
\text { Correct design before the construction starts }\end{array}$ \\
\hline 2 & A & Medical Building & $\begin{array}{l}\text { Identify new uses and services to clients } \\
\text { Engage client for future work }\end{array}$ \\
\hline 3 & A & School Building & $\begin{array}{l}\text { Lower costs } \\
\text { Optimize schedules } \\
\text { Engage occupants } \\
\text { Collect proper and timely feedback }\end{array}$ \\
\hline 4 & A & Medical Building & $\begin{array}{l}\text { Aid in budgeting } \\
\text { Improve workflow } \\
\text { Resolve field conflicts } \\
\text { Correct design before the construction starts } \\
\text { Allow for quality control }\end{array}$ \\
\hline 5 & B & Medical Building & $\begin{array}{l}\text { Lower costs } \\
\text { Optimize schedules } \\
\text { Engage occupants } \\
\text { Collect proper and timely feedback } \\
\text { Correct design before the construction starts }\end{array}$ \\
\hline 6 & B & Headquarter & $\begin{array}{l}\text { Tailor each of its customers VR experience specific to their needs } \\
\text { Correct design before the construction starts }\end{array}$ \\
\hline 7 & B & Medical Building & $\begin{array}{l}\text { Lower costs } \\
\text { Optimize schedules } \\
\text { Engage occupants } \\
\text { Collect proper and timely feedback } \\
\text { Use portable VR to enable working around the staff work schedule } \\
\text { Correct design before the construction starts }\end{array}$ \\
\hline 8 & $\mathrm{C}$ & $\begin{array}{l}\text { High Rise Apartment } \\
\text { Building }\end{array}$ & $\begin{array}{l}\text { Easy to access for the stakeholders } \\
\text { Optimize schedules } \\
\text { Aid in construction site planning } \\
\text { Improve safety } \\
\text { Engage stakeholders } \\
\text { Collect proper and timely feedback }\end{array}$ \\
\hline 9 & $\mathrm{D}$ & Campus Building & $\begin{array}{l}\text { Engage stakeholders } \\
\text { Collect proper and timely feedback } \\
\text { Crowdsource information essentially } \\
\text { Improve safety } \\
\text { Enhance communication } \\
\text { Lower costs } \\
\text { Optimize schedules }\end{array}$ \\
\hline \multirow[t]{2}{*}{10} & $\mathrm{E}$ & $\begin{array}{l}\text { Indoor Trampoline } \\
\text { Center }\end{array}$ & $\begin{array}{l}\text { Set the company apart from their competitors } \\
\text { Enhance collaboration and communication throughout the project } \\
\text { Increase safety } \\
\text { Improve visualization } \\
\text { Lower costs } \\
\text { Optimize schedules }\end{array}$ \\
\hline & $\mathrm{E}$ & Multi-use Building & $\begin{array}{l}\text { Enhance collaboration and communication throughout the project } \\
\text { Improve safety } \\
\text { Improve visualization } \\
\text { Lower costs } \\
\text { Optimize schedules }\end{array}$ \\
\hline 11 & $\mathrm{~F}$ & Land Port of Entry & $\begin{array}{l}\text { Lower costs } \\
\text { Optimize schedules } \\
\text { Improve safety } \\
\text { Aid in design reviews } \\
\text { Engage stakeholders } \\
\text { Collect proper and timely feedback }\end{array}$ \\
\hline
\end{tabular}


Table 3. Cont'd

12

G

Multiple Projects

13

H Medical Building

14

I Medical Building

15

16

17

18

19
J Medical Building

J Campus Building

J Campus Building

K Medical Building

K Medical Building

L Multiple Projects

M Medical Building

N River Walkway

O Office building

P Headquarter

Q Multiple Projects

R Medical Building
Provide a safe and effective way to train welders/trades without exposing the trainees to the possible inherent dangers

Improve safety

Lower costs

Optimize schedules

Aid in design reviews

Engage stakeholders

Collect proper and timely feedback

Lower costs

Optimize schedules

Aid in design reviews

Enhance collaboration and communication between designer and user

Adjust spatial dimensioning on fixed equipment

Make changes to fixed equipment before construction

Lower costs

Optimize schedules

Aid in design reviews

Lower costs

Improve safety

Create a cloud-based system for information sharing

Minimize site logistics risk and tower crane risk

Enable student-related services running during the project

Enhance collaboration and communication

Lower costs

Improve safety

Improve customer satisfaction

Enable faster decision making

Lower costs

Improve design productivity

Decrease re-work

Lower costs

Optimize schedules

Shorten design time

Aid in design reviews

Allow a complete understanding of specific site conditions and dangerous areas

Improve safety

Collect proper and timely feedback

Correct design before the construction starts

Increase visualization

Improve customer satisfaction

Increase visualization

Lower costs

Optimize schedules

Decrease re-work

Shorten design time

Increase design efficiency

Enhance collaboration and communication

Improve workflow integration

Decrease time of rendering

Increase design efficiency

Enhance collaboration and communication

Improve customer satisfaction

Prevent clashes

Improve fabrication

Collect proper and timely feedback

Correct design before the construction starts

Increase visualization

Improve customer satisfaction 


\section{Findings and discussions}

\subsection{Discussion of main uses of $V R$}

The distribution of these four main uses among twenty-seven (27) case studies are presented in Fig.

2. The largest category is performing design reviews with more than half of the case studies reporting repeated use of immersive VR for occupant reviews, presenting the finished $3 \mathrm{D}$ model to clients and occupants, helping occupants understand the changes to the building, and collecting timely feedback from occupants for general as well as sensitive situations. With the abundance of medical buildings in the data set, performing BIM mockups in 3D and analyzing situations such as design fit to the desired functionality of the new space and improved fit of expensive equipment such as MRI equipment highlights the importance of having VR technology in hand. Monitoring the construction process comes as the second largest with one quarter of cases using VR for mapping out the entire construction process, analyzing placement of large equipment like cranes, and integrating safety practices while planning site logistics. Performing project coordination is third in the list, which is very surprising due to the fact that GC companies occasionally deal with various building systems and checking their interferences. In this data set, some cases used VR for MEP fittings and clash detection, but it was not majorly used in other projects. One reason of this was reported to be the requirement of a completed 3D model/BIM to be able to analyze clashes related to MEP systems.

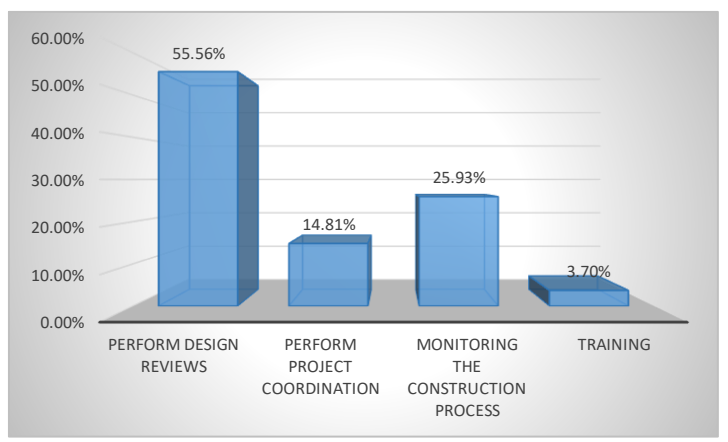

Fig. 2. Percent Distribution of Various VR Uses
This statement is also in line with the challenges identified as "Preparation of the 3D Model" and "Lack of Streamlined Software". When the subcontractors do not use Revit or any other BIM software, it is not possible to have a complete 3D model. Even if they use some type of BIM software, a common software needs to be identified to keep the flow of information within BIM and from BIM to the VR system. Without a unified 3D building model with all systems, VR walk-throughs for project coordination cannot be performed successfully. Many of the interviewees stated the lack of common software platforms to hinder the adaptation and use of VR technology for certain projects. The fourth use was using VR for training. Although many subcontractors prefer to train workers with VR for a specific task or skill, it was not common around the GC companies interviewed.

\subsection{Discussion of VR benefits and enablers}

A quantitative analysis of the VR enablers was performed by using the collected data. Acording to the Fig. 3, around $81 \%$ of the respondents agreed that the use of immersive VR technology during their projects improved communication, collaboration, and/or coordination among project stakeholders. Engagement of occupants and clients at the early stages of the project increased design efficiency and enabled parties to correct the design before the construction starts. Design review benefits resulted in more valuable and long-term benefits such as improving customer satisfaction and engaging clients for future work. Though client engagement and sustainability were not one of the main goals of implementing VR, the adaptation of the VR process ended up attracting more customers.

$93 \%$ of the projects directly reported cost and time savings, while the rest documented cost and time savings as secondary benefits to improving safety and/or construction site process. $85 \%$ of the case studies ranked improving design review as one of the most important enablers due to its ability to streamline the occupant-related decision process and prevent design changes during construction and occupancy. Aid in design review yielded in lower 
costs in all cases due to two reasons: (1) decreased change orders and (2) VR mockup costing around $15 \%$ less than a proposed physical mockup. The overall design review process enabled GC parties to collect proper and timely feedback and coordinate with design parties to correct design before the construction starts. In some cases, virtual walkthroughs yielded more than 35 suggested changes, which were corrected during the pre-construction phase. The popularity of VR for design reviews rooted in its improved visualization as well as offering easy to access for the stakeholders. After its set up, VR learning curve was reported to be fairly quick that clients and occupants of the building such as doctors and nurses could easily use the immersive VR system. Although not as highly ranked as improving design reviews, improving safety/training was ranked at $33 \%$ by the interviewees. VR technology provided a safe and effective way to train workers for potentially dangerous situations. Improving safety was not only linked to safe training opportunities, but also linked to improving construction site process as an enabler. Improving construction site process was ranked around $7 \%$ in terms of VR use in the case studies. Through it seems as a lower ranking, VR technology helped to understand specific site conditions and prevent site logistics risks.

\subsection{SWOT analysis for VR implementation}

Strengths, Weaknesses, Opportunities, and Threats (SWOT) analysis has been traditionally used to identify strengths and weaknesses related to a topic that are internal to a person or company, so that they will learn items that they have control over.

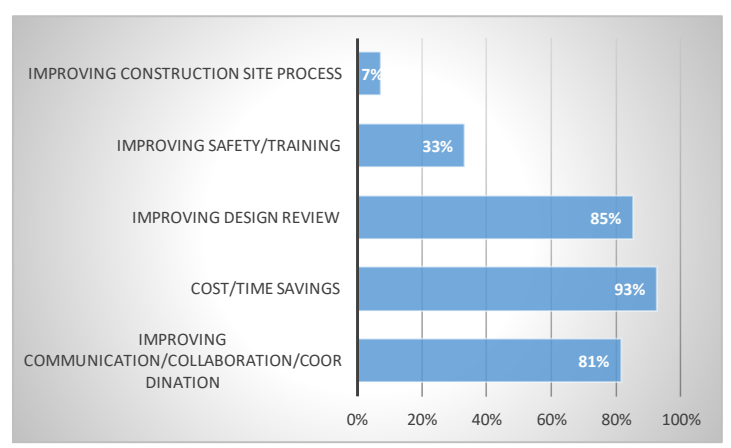

Fig. 3. Rating of enablers from case studies
On the other hand, opportunities and threads are identified as external items that have potential to improve or worsen the situation and that are outside the control of the person or company. Companies can plan to benefit from opportunities and protect themselves from threats for possible future scenarios. In this study, SWOT analysis is used to guide construction companies to successfully implement the VR technology. Considering the main uses of VR and benefits and enablers from construction companies perspectives, strengths, weaknesses, opportunities, and threats are identified in Fig. 4.

Companies that would like to implement immersive VR will benefit from improved design reviews and customer relationships due to the ability to streamlining the design process and correcting design before starting the construction process. This would decrease the number of change orders tremendously and give companies the opportunity to save time and cost. Therefore, implementing VR technology is worthy of its value. However, companies new to VR should be careful in creating the 3D BIM model and making sure all stakeholders are using common or related software applications. The success of the virtual walkthroughs depends mainly on the virtual environment created. The 3D virtual building environment should be created in detail. This process requires companies personnel to have VR training. Additionally, related personnel should keep themselves up to date with emerging VR technologies. The first cost of hardware and software applications and training of personnel may seem high for small-size companies, however longterm benefits on large construction projects would pay off companies' investment on VR.

Considering the results of this study, a VR Implementation Framework for Construction Companies is suggested in Fig. 5. Companies are suggested to set a main goal and use of VR before considering virtual walk-throughs in construction projects. The main uses of VR were mentioned in this study. As an example, if the main use is to perform design reviews with clients or occupants, a suitable immersive VR technology should be 


\section{Strengths}

- Improved communication

- Improved project coordination

- Successful clash detection

- 3D virtual mock-ups

- Improved design reviews

- Improved visualization

- Providing a safe training
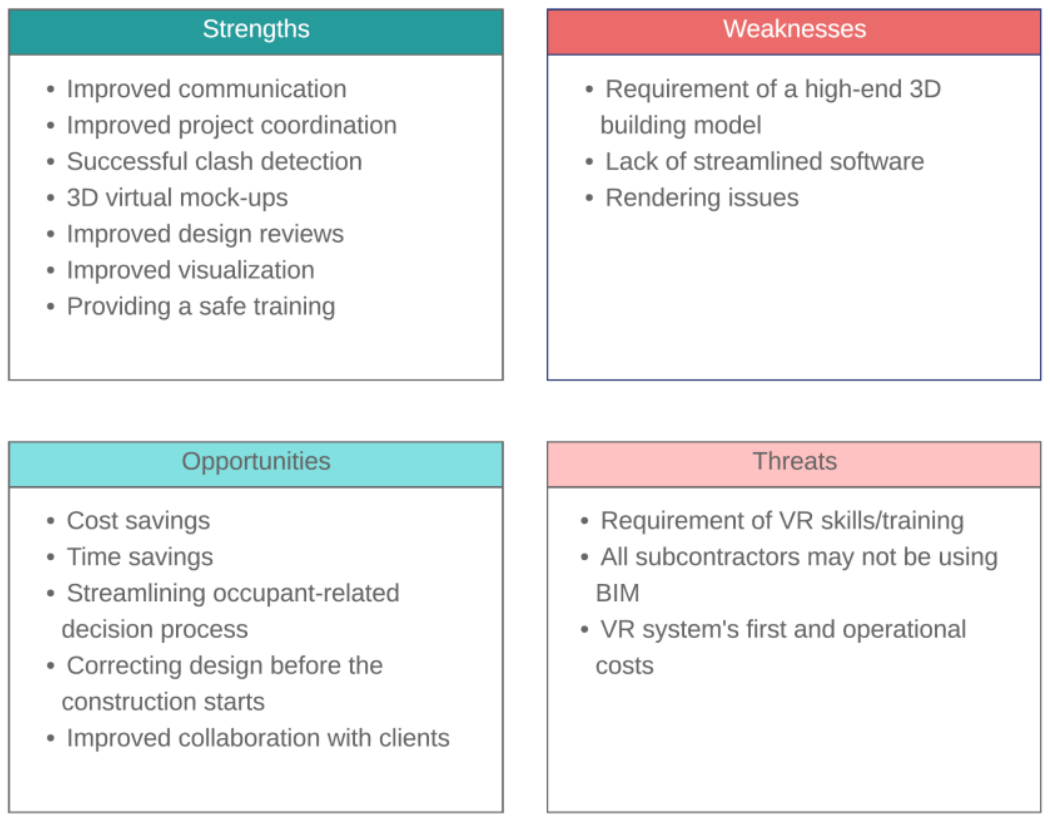

Fig. 4. SWOT analysis of VR implementation

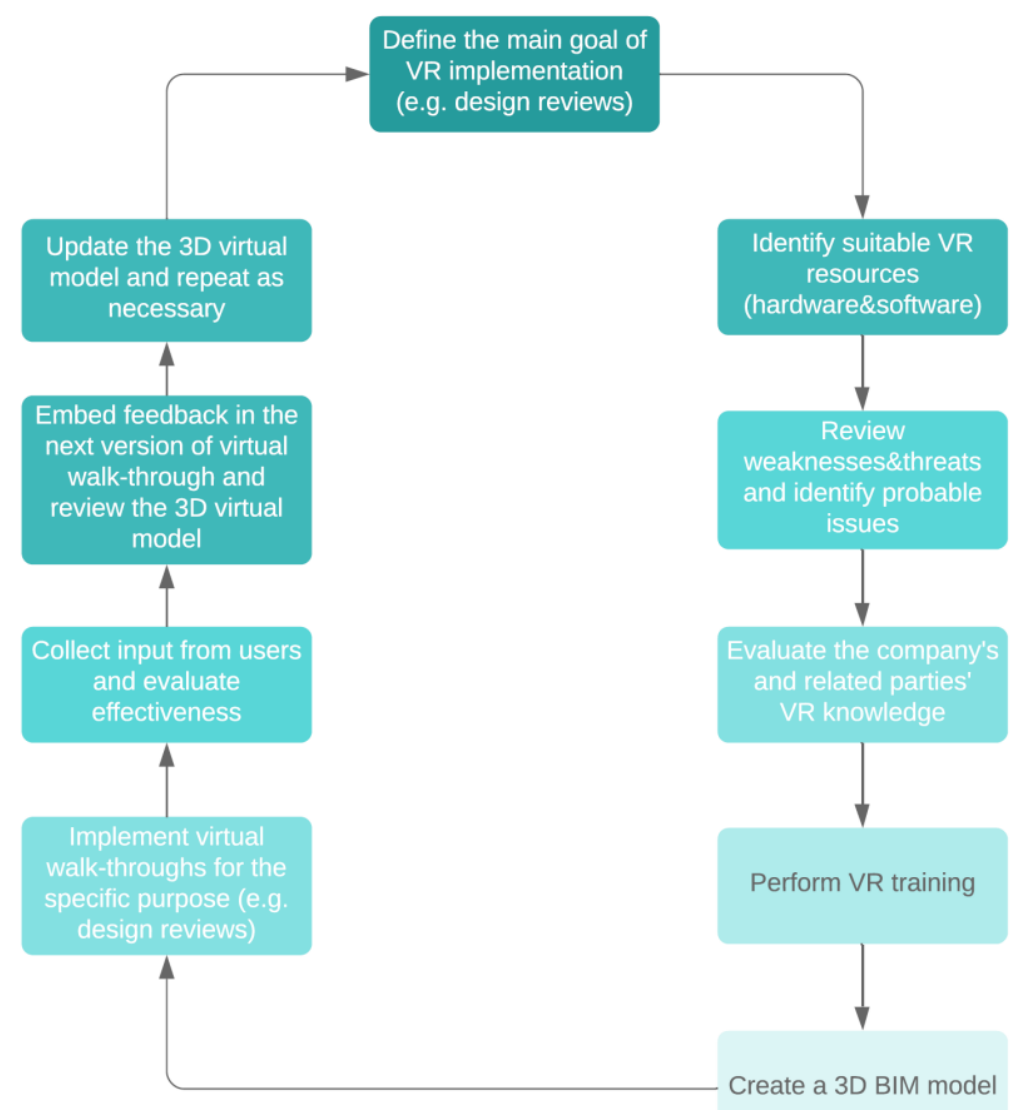

Fig. 5. VR implementation framework for construction companies 
selected. VR equipment should be set at a location that is convenient for all parties. SWOT analysis performed in this study will help new practitioners to have potential issues in hand in a generic fashion. Users should evaluate company's and other parties VR knowledge and train parties as necessary to ease the use of this technology and prevent potential issues. After all parties are ready, 3D building model should be created with the goal of VR in mind. Virtual walk-throughs should be performed several times to collect input from users and revise the $3 \mathrm{D}$ model. The iterative process will allow to improve the 3D model and the virtual walk-through process.

\section{Conclusions}

The current practice of VR allows various benefits to construction practitioners through virtual walkthroughs in different stages of the construction projects. A total of eighteen (18) companies were interviewed in this study to collect VR-related construction industry data in twenty-seven (27) case studies. Participants were asked about their use of the VR technology and about the enablers and challengers of VR as defined in this research. Findings revealed the main uses of VR as for: (1) Design reviews for clients and occupants, (2) Project coordination, (3) Monitoring the construction process, and (4) Training. More than half of the cases reported to use VR to aid design reviews, engage clients and occupants, and collect timely feedback to change design before the construction starts. Major benefits and enablers for GC companies were identified as Improving Communication/Collaboration/Coordination', 'Cost/Time Savings', 'Improving Design Review', Improving Safety/Training', and 'Improving Construction Site Process'. Both literature review and the analysis of data emphasized the positive impact of virtual walk-throughs on decreasing cost and improving schedule as the most important benefit for GC companies. Direct of indirect cost savings were achieved by streamlining the design process and improving communications with the project stakeholders. Following cost/time savings, improving design reviews was second and improving collaboration / communication / coordination was third in the list of enablers. Improving safety/training and improving construction process was ranked as the least common enablers of VR for GC companies. It can be concluded that the majority of the GC companies adopt VR technology to decrease design changes and consequently change orders, which has been the major source of delays in all types of construction projects. Specifically, medical projects employed VR to understand specific occupant needs and preferences. As medical buildings require unique features and installation of fixed equipment, it makes VR a necessity to fulfill the needs of the client and occupants simultaneously.

The most widely used VR technology was found to be HMDs with HTC Vive and Oculus Rift to be the two most widely used VR systems. Both systems are fully immersive and allows users to immersive in a virtual environment. As both systems are based on traditional gaming platform, their learning curve is considerably short, and they include tutorials for first-time users such as building occupants. With the improved visualization, users can markup design changes and even in some cases occupants can move objects in the virtual environment. A good example of this is nurses and doctors moving the location of items in a surgery room. Some companies used CAVE system as designated virtual environment, while some others created a virtual environment through 360-degree photos. In the overall, all GC companies interviewed during this study has been using one or the other type of an immersive VR system with a $3 \mathrm{D}$ virtual model.

The majority of the companies used a 3D model as a virtual environment that was created by a BIMbased modeling process. Although BIM is widely used in the industry, linking 3D models to VR systems has not been standardized yet. One issue has been the creation of a proper 3D model, as creating the model by various stakeholders up to the required level of development is the first step to start VR implementation. Virtual walk-throughs cannot be performed without a detailed 3D model, which is one property that distinguishes VR from 
Augmented Reality (AR). AR uses a real environment with some additions vs. VR required a complete 3D virtual environment to immerse its users. As the next challenger, even with a complete and detailed 3D model created by BIM, the information in the BIM software needs to go through several steps to be transferred to the VR software. HMDs like HTC Vive and Oculus Rift come with their own VR software applications, but the transfer of a 3D/Revit model to the VR software requires additional software applications. That would bring a small-size company additional cost to buy and maintain software licenses, and also train personnel on the use of VR. One other challenger that came up during the interviews but was not stated in the literature was the requirement to constantly improve the VR knowledge. Even if GC companies have had a set VR system with all personnel, hardware, and software requirements, the VR specialist needs to be kept updated with the technology and equipment due to the fast and continuous evolvement of the VR systems. In addition to the monetary requirements, keeping up with the evolving technology is also a challenge for relatively small GC companies. It was observed that medium to large-sized GC companies have streamlined the use of the VR process for design reviews to receive added benefits of cost, schedule, collaboration and safety.

This study also revealed the major business drivers for GC companies to adopt VR technology. Understanding client needs in the early stages of the project and involving them in the design decisionmaking resulted in improved customer satisfaction. Engaging clients for future work and setting the company apart from competitors have become main drivers of using VR for the majority of the companies.

This paper revealed the most frequently used VR technology, VR benefits, and VR main uses from GC companies' point of view. Results showed the companies' continued investment and commitment to the emerging VR technology, as well as its benefits in the construction industry. As one of the limitations, all data was collected from U.S. GC companies and projects. Same methodology can be applied to international projects to evaluate VR main uses, benefits, enablers and challengers in different companies. As this paper presented reviews of industry practitioners, future studies are planned to compare applications of VR in academia vs. in construction industry to close the gap of knowledge between educators and practitioners. Due to the requirement and importance of VR training, it would be tremendously beneficial to train future $\mathrm{CM}$ graduates with this valuable technology, so that they would contribute to GC companies in their VR applications.

\section{References}

[1] Kalawsky R. Exploiting Virtual Reality Techniques in Education and Training: Technological Issues, SIMA Report Series ISSN 1356-5370, Loughborough, UK, 1996.

[2] Winn WA. Conceptual basis for educational applications of virtual reality, University of Washington, Seattle, WA, 1993.

[3] Felnhofer A, Kothgassner O, Schmidt M, Heinzle A, Beutl L, Hlavacs H, Kryspin-Exner I (2015). Is virtual reality emotionally arousing? Investigating five emotion inducing virtual park scenarios, International Journal of Human-Computer Studies, 82: 48-56.

[4] Sacks R, Whyte J, Swissa D, Raviv G, Zhou W, Shapira A (2015). Safety by design: dialogues between designers and builders using virtual reality, Construction Management and Economics, 33(1): 55-72.

[5] Kamat VR, Martinez JC, Fischer M, GolparvarFard M, Peña-Mora F, Savarese S (2010). Research in visualization techniques for field construction, Journal of construction engineering and management, 137(10), 853-862.

[6] Woodward C, Hakkarainen M, Korkalo O, Kantonen T, Aittala M, Rainio K, Kähkönen K. Mixed reality for mobile construction site visualization and communication, in 10th International Conference on Construction Applications of Virtual Reality (CONVR), 2010, Sendai, Japan.

[7] Shen W, Hao Q, Mak H, Neelamkavil J, Xie H, Dickinson J, Thomas R, Pardasani A, Xue H (2010). Systems integration and collaboration in architecture, engineering, construction, and 
facilities management: A review, Advanced Engineering Informatics, 24(2), 196-207.

[8] Whyte J (2003). Industrial Applications of Virtual Reality in Architecture and Construction, ITcon, 8: 43.

[9] Furness T. Configuring virtual space for the super cockpit, Human Interface Technology Laboratory Technical Report HITL-M-89-1, 1989, Seattle, WA.

[10] Peters C, Postlethwaite D, Wallace M. Systems and methods providing enhanced education and training in a virtual reality environment, 2016, Google Patents.

[11] Fang Y, Teizer J, Marks E. A framework for developing an as-built virtual environment to advance training of crane operators, in Construction Research Congress (CRC) 2014: Construction in a Global Network, 2014, Atlanta, GA.

[12] Le Q, Pedro A, Park C (2015). A social virtual reality based construction safety education system for experiential learning, Journal of Intelligent \& Robotic Systems, 79(4), 487-506.

[13] Zhao D, Lucas J (2015). Virtual reality simulation for construction safety promotion. International Journal of Injury Control and Safety Promotion, 22(1), 57-67.

[14] Haymaker J, Fischer M. Challenges and benefits of 4D modeling on the Walt Disney Concert Hall Project, 2001, Stanford University, Stanford, CA.

[15] Messner J, Yerrapathruni S, Baratta A, Whisker V. Using Virtual Reality to Improve Construction Engineering Education, in Proceedings of the 2003 American Society for Engineering Education Annual Conference \& Exposition, 2003, Nashville, TN.

[16] Hilfert T, König M (2016). Low-cost virtual reality environment for engineering and construction, Visualization in Engineering, 4(1): 2.

[17] Bastug E, Bennis M, Medard M, Debbah M (2017). Toward Interconnected Virtual Reality: Opportunities, Challenges, and Enablers, IEEE Communications Magazine, 55(6): 110-117.

[18] Haggard K. Case Study on Virtual Reality in Construction, California Polytechnic State University, 2017, San Luis Obispo, CA.

[19] Nikolic D, Lee S, Zappe S, Messner J (2015). Integrating Simulation Games into Construction Curricula: The VCS3 Case Study, International Journal of Engineering Education, 31: 1661-1677.
[20] Li H, Chan G, Skitmore M (2012). Visualizing safety assessment by integrating the use of game technology, Automation in Construction, 22: 498505.

[21] Dickinson J, Woodard P, Canas R, Ahamed S, Lockston D (2011). Game-based trench safety education: Development and lessons learned, ITcon, 16: 119-134.

[22] Lin K-Y, Son J, Rojas E (2011). A pilot study of a 3D game environment for construction safety education, ITcon, 16: 69-84.

[23] Su X, Dunston P, Proctor R, Wang X (2013). Influence of training schedule on development of perceptual-motor control skills for construction equipment operators in a virtual training system, Automation in Construction, 35: 439-447.

[24] Dunston P, Arns L, Mcglothlin J, Lasker G, Kushner A. An Immersive Virtual Reality MockUp For Design Review, in 7th International Conference on Construction Applications of Virtual Reality (CONVR), 2007, State College, PA.

[25] Hartless J, Borders J, Lam C, Ayer S, London J, Wu W. A New Approach to Testing Augmented- and Virtual-Reality to Support Tacit Knowledge Generation in Design Assessment, in 18th International Conference on Construction Applications of Virtual Reality (CONVR), 2018, Auckland, New Zealand.

[26] Thabet W, Shiratuddin M, Bowman D. Virtual Reality in Construction: A Review, in Engineering Computational Technology, Saxe-Coburg Publications, Edinburgh, UK, 2002, 25-52.

[27] Barsoum A, Hadipriono F, Larew R. Avoiding falls from Scaffolsing in Virtual World, in 3rd Congress in Computing in Civil Engineering, 1996.

[28] Li H, Chan G, Skitmore M (2012). Multiuser virtual safety training system for tower crane dismantlement, Journal of Computing in Civil Engineering, 26: 638-647.

[29] Li X, Yi W, Chi H-L, Wang X, Chan A (2018). A critical review of virtual and augmented reality (VR/AR) applications in construction safety, Automation in Construction, 86: 150-162.

[30] Cheng T, Teizer J (2013). Real-time resource location data collection and visualization technology for construction safety and activity monitoring applications, Automation in Construction, 34: 3-15. 
[31] Retik A (1997). Planning and monitoring of construction projects using virtual reality, Project Management Journal, 3(97), 28-32.

[32] Boussabaine A, Grew B, Cowland S, Slater P. A Virtual Reality Model for Site Layout, in The 5th International Conference on The Application of Artificial Intelligence to Civil and Structural Engineering (CIVIL-COMP99 \& AICIVILCOMP99), 1999, Oxford, UK.

[33] Al-Adhamia M, Maa L, Wua S. Exploring Virtual Reality in Construction, Visualization and Building Performance Analysis, in 35th International Symposium on Automation and Robotics in Construction (ISARC 2018), 2018, Berlin, Germany.

[34] Whyte J, Bouchlaghem D, Thorpe A. The Promise and Problems of Implementing Virtual Reality In Construction Practice, in CIB, 1998, Stockholm, Sweden.

[35] Chen A, Golparvar-Fard M, Kleiner B. Design and Development of SAVES: A Construction Safety Training Augmented Virtuality Environment for Hazard Recognition and Severity Identification, in International Workshop on Computing in Civil Engineering, 2013, Los Angeles, CA.

[36] Shen Z, Jiang L, Grosskopf K, Berryman C. Creating 3D web-based game environment using BIM models for virtual on-site visiting of building HVAC systems, in Construction Research Congress, 2012, West Lafayette, IN.

[37] Eastman C, Teicholz P, Sacks R, Liston K. BIM handbook: A guide to building information modeling for owners, managers, designers, engineers and contractors, John Wiley \& Sons, 2011, Hoboken, NJ.

[38] Halaby J. Simulating Presence: BIM to Virtual Reality, in Presentation at BAYA: Emerging Technologies in Architecture, 2015, San Francisco, CA.

[39] Wang X, Dunston P (2007). Design, Strategies, and Issues Towards An Augmented Reality-Based Construction Training Platform, ITcon, 12: 363380.

[40] Klinker G, Stricker D, Reiners D. Augmented Reality for Exterior Construction Applications, in Fundamentals of Wearable Computers and Augmented Reality, Lawrence Erlbaum Associates, 2001, Mahwah, NJ, 379-427.

[41] Chen C-H, Yang J-C, Shen S, Jeng M-C (2007). A Desktop Virtual Reality Earth Motion System In
Astronomy Education, Journal of Educational Technology \& Society, 10: 289-304.

[42] Ozcan-Deniz G. An Application of BIM-Based Virtual Punch Listing in Construction, in 12th BIM Academic Symposium \& Job Task Analysis Review, 2018, Orlando, FL.

[43] Waly A, Thabet W (2003). A Virtual Construction Environment for Preconstruction Planning," Automation in Construction, 12: 139-154.

[44] Cruz-Neira C, Sandin D, DeFanti T. SurroundScreen Projection-Based Virtual Reality: The Design and Implementation of the CAVE, in Proceedings of ACM SIGGRAPH, 1993, Anaheim, CA.

[45] ENR, (2018) Available: https://www.enr.com/toplists/2018-Top-400Contractors1. [Accessed 2003 2019].

[46] BD+C, Building Design and Construction, (2017) Available: https://www.bdcnetwork.com/top-110healthcare-construction-firms. [Accessed 2003 2019].

[47] Oculus, Oculus-Rift Overview (2019) Available: https://www.oculus.com/rift/\#oui-csl-riftgames=mages-tale. [Accessed 1803 2019].

[48] Farahani N, Post R, Duboy J, Ahmed I, Kolowitz B, Krinchai T, Monaco S, Fine J, Hartman D, Pantanowitz L (2016). Exploring Virtual Reality Technology and the Oculus Rift for the Examination of Digital Pathology Slides, Journal of Pathology Informatics, 7: 22.

[49] HTC Vive, Vive Virtual Reality System (2019) Available: https://www.vive.com/us/product/vivevirtual-reality-system/. [Accessed 1803 2019].

[50] SteamVR, Virtual Reality on Steam (2019) Available: http://store.steampowered.com/vr/. [Accessed 1501 2019].

[51] IrisVR, Instant Virtual Reality for the Building Industry (2019) Available: https://irisvr.com/. [Accessed 1803 2019].

[52] WorldViz, WorldViz - Virtual Reality Creation and Collaboration (2019) Available: https://www.worldviz.com/virtual-reality-designdevelopment. [Accessed 2003 2019].

[53] ContextVR, Context VR - About (2019) Available: https://www.contextvr.com/. [Accessed $20 \quad 03$ 2019].

[54] HoloBuilder, Capture your construction site in $360^{\circ}$ (2019) Available: https://www.holobuilder.com/. [Accessed 2003 2019]. 